\section{Unihemispheric burst suppression}

\author{
Edward C. Mader Jr., Nicole R. \\ Villemarette-Pittman, Cornel T. Rogers, \\ Frank Torres-Delgado, Piotr W. \\ Olejniczak, John D. England
}

Epilepsy Center of Excellence, Louisiana State University Health Sciences Center, New Orleans, LA, USA

\section{Abstract}

Burst suppression (BS) consists of bursts of high-voltage slow and sharp wave activity alternating with periods of background suppression in the electroencephalogram (EEG). When induced by deep anesthesia or encephalopathy, BS is bihemispheric and is often viewed as a non-epileptic phenomenon. In contrast, unihemispheric BS is rare and its clinical significance is poorly understood. We describe here two cases of unihemispheric BS. The first patient is a 56-year-old woman with a left temporoparietal tumor who presented in convulsive status epilepticus. EEG showed left hemispheric BS after clinical seizure termination with lorazepam and propofol. The second patient is a 39-year-old woman with multiple medical problems and a vague history of seizures. After abdominal surgery, she experienced a convulsive seizure prompting treatment with propofol. Her EEG also showed left hemispheric BS. In both cases, increasing the propofol infusion rate resulted in disappearance of unihemispheric BS and clinical improvement. The prevailing view that typical bihemispheric BS is non-epileptic should not be extrapolated automatically to unihemispheric BS. The fact that unihemispheric BS was associated with clinical seizure and resolved with propofol suggests that, in both cases, an epileptic mechanism was responsible for unihemispheric BS.

\section{Introduction}

Burst suppression (BS) is an abnormal pattern in the electroencephalogram (EEG) where bursts of high-voltage slow waves and sharp waves alternate with periods of depressed background activity. ${ }^{1}$ The bursts are generally bihemispheric and more or less bisynchronous and bisymmetric. Bihemispheric BS is invariably associated with coma, usually in the setting of deep anesthesia, drug intoxication, hypothermia, and cerebral anoxia. Although BS has been studied extensively at the EEG level, only sparse information is available in regards to its neurophysiological mecha- nisms. ${ }^{2}$ Current clinical practice is based on the interpretation of BS as a non-epileptic phenomenon.

Bihemispheric BS has occasionally been observed to be asymmetric and/or asynchronous. In patients with unihemispheric lesions (e.g. hemimegalencephaly) asymmetric BS may occur spontaneously and disappear in infancy or it may persist into adult life. ${ }^{3}$ Anesthesia-induced asymmetric and asynchronous BS in patients with lesions of the corpus callosum indicates that this structure plays a crucial role in interhemispheric synchronization of normal and abnormal cortical electrical activity. ${ }^{4,5}$ On the other hand, true unihemispheric $\mathrm{BS}$ is rare and its clinical significance is poorly understood. In this paper, we describe two patients with unihemispheric BS while being treated with propofol for epileptic seizures.

\section{Case Report \#1}

Patient A is a 56-year-old woman with a left temporoparietal solitary metastatic brain lesion ( $\mathrm{s} / \mathrm{p}$ resection) who presented in convulsive status epilepticus. She was taking levetiracetam $1000 \mathrm{mg} /$ day and phenytoin 450 $\mathrm{mg}$ /day at home. Clinical seizure termination was achieved with fosphenytoin $1000 \mathrm{mg}$, lorazepam $4 \mathrm{mg}$, and propofol $2 \mathrm{mg} / \mathrm{kg}$ load then $2 \mathrm{mg} / \mathrm{kg} / \mathrm{hr}$. EEG recording 45 minutes after seizure termination showed unihemispheric BS on the left and background slowing on the right (Figure 1). Unihemispheric BS persisted when the propofol infusion rate was $2 \mathrm{mg} / \mathrm{kg} / \mathrm{hr}$. Its disappearance 4 hours later coincided with a propofol drip rate of 5 $\mathrm{mg} / \mathrm{kg} / \mathrm{hr}$. Propofol was discontinued after 12 hours with no recurrence of seizure or unihemispheric BS. Brain magnetic resonance imaging showed left anterior parietal encephalomalacia with surrounding edema and mass effect prompting treatment with dexamethasone. Prior to discharge, follow-up EEG showed left hemispheric slowing with no recurrence of unihemispheric BS.

\section{Case Report \#2}

Patient B is a 39-year-old woman whose past seizures were attributed to alcohol withdrawal; she was not taking antiepileptic drugs at home. She had a generalized tonic-clonic seizure after undergoing surgery for a bleeding duodenal ulcer. Clinical seizure termination was achieved with intravenous levetiracetam $1000 \mathrm{mg}$ and propofol $2 \mathrm{mg} / \mathrm{kg}$ load then $2 \mathrm{mg} / \mathrm{kg} / \mathrm{hr}$. EEG recording 30 minutes after seizure termination showed unihemispheric
Correspondence: Edward C. Mader, Jr., Epilepsy Center of Excellence, Louisiana State University School of Medicine, 1542 Tulane Avenue, New Orleans, LA 70112, USA

Tel.: + 1.504.568.4080 - Fax: +1.504.617.60974

E-mail: emader@Isuhsc.edu

Key words: burst suppression, unihemispheric, electroencephalogram, seizure, status epilepticus, propofol.

Acknowledgments: the authors are grateful to their electroencephalogram technologists Thomas B. Miller, Terri L. Ware, and Sheryl A. Wagamotte.

Contributions: ECM, CTR, FTD, direct patient care, EEG interpretation, and preparation of manuscript; NRVP, PWO, JDE, literature search, review, editing, and finalizing manuscript.

Conflict of interests: the authors declare no potential conflict of interests.

Received for publication: 21 May 2014

Accepted for publication: 7 July 2014.

This work is licensed under a Creative Commons Attribution NonCommercial 3.0 License (CC BYNC 3.0).

(C) Copyright E.C. Mader Jr. et al., 2014

Licensee PAGEPress, Italy

Neurology International 2014; 6:5487

doi:10.4081/ni.2014.5487

BS on the left but not on the right (Figure 2). EEG monitoring continued to demonstrate left unihemispheric BS with propofol infusion at 2 $\mathrm{mg} / \mathrm{kg} / \mathrm{hr}$. Unihemispheric BS disappeared 2 hours later at a time when the propofol drip rate was $5 \mathrm{mg} / \mathrm{kg} / \mathrm{hr}$. Propofol was discontinued after 18 hours with no recurrence of seizure and unihemispheric BS. Brain computed tomography scan revealed left hemispheric encephalomalacia with predominant involvement of the left posterior parietal lobe. Followup EEG showed complete resolution of unihemispheric BS and normalization of the EEG.

\section{Discussion}

Clinically, BS is almost always bihemispheric and is often bilaterally synchronous and symmetric. As in the two cases described in this paper, BS can also be restricted to one hemisphere. However, the dearth of published data on unihemispheric BS suggests that this entity is rare, frequently ignored, or poorly understood. The pathophysiological basis of BS is not well understood. Two mechanisms have been implicated through research in this area: cerebral hypometabolism and thalamo- 


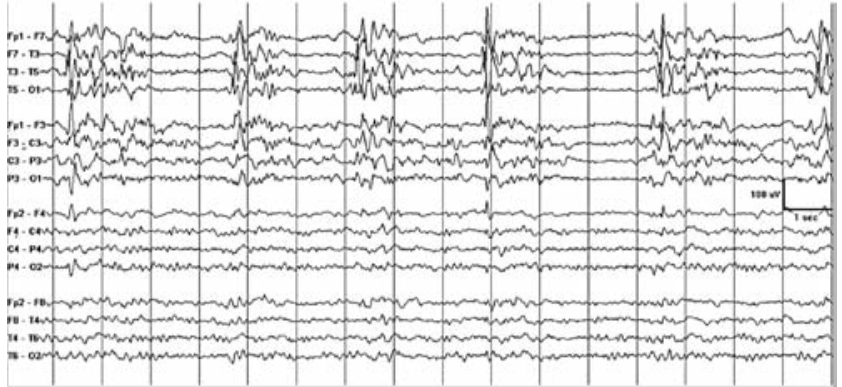

Figure 1. Electroencephalogram of Patient A showing left-sided burst suppression 45 minutes after status epilepticus termination with fosphenytoin $1000 \mathrm{mg}$, lorazepam $4 \mathrm{mg}$, and propofol 2 $\mathrm{mg} / \mathrm{kg}$ load. The occasional right-sided sharp waves that stand out against the low-amplitude slow background activity are most likely the result of volume conduction from the left hemisphere source. Unihemispheric burst suppression persisted as propofol was being infused at $2 \mathrm{mg} / \mathrm{kg} / \mathrm{hr}$ and disappeared 4 hours later when the infusion rate was $5 \mathrm{mg} / \mathrm{kg} / \mathrm{hr}$. Propofol was discontinued after 12 hours with no recurrence of seizure activity and unihemispheric burst suppression.

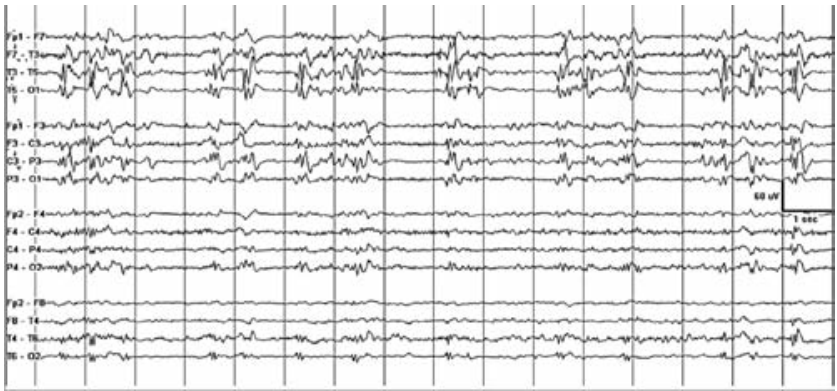

Figure 2. Electroencephalogram of Patient B showing left-sided burst suppression 30 minutes after clinical seizure termination with intravenous levetiracetam $1000 \mathrm{mg}$ and propofol $2 \mathrm{mg} / \mathrm{kg}$ load. Fragments of burst activity spilling over the right hemisphere are most likely due to volume conduction from the left hemisphere source. Unihemispheric burst suppression was present during propofol infusion at $2 \mathrm{mg} / \mathrm{kg} / \mathrm{hr}$. It disappeared 2 hours later when the propofol infusion rate was $5 \mathrm{mg} / \mathrm{kg} / \mathrm{hr}$. Propofol was discontinued after 18 hours with no recurrence of seizure and unihemispheric burst suppression. cortical hyperexcitability.

The hypometabolism theory considers brain hypometabolism during EEG suppression as the fundamental physiological disturbance in BS. ${ }^{6}$ The burst of synchronous activity is simply viewed as a reaction of the brain to prevent membrane potential collapse during the hypometabolic state. This theory is consistent with the fact that BS can be induced by a variety of conditions that reduce cerebral metabolic rate, including hypothermia, ${ }^{7}$ hypoxicischemic encephalopathy, ${ }^{8}$ and general anesthesia. ${ }^{9}, 10$ Moreover, classical BS is consistently induced with gamma-aminobutyric acid enhancing drugs that significantly reduce cerebral metabolic rate, but not with ketamine and other anesthetic agents that do not decrease cerebral metabolic rate at clinically relevant doses. ${ }^{10}$

The hyperexcitability theory emphasizes abnormal cortical and thalamic bursting activity as the basic mechanism driving BS.11 Intracellular recording of cortical neurons during the EEG burst revealed the presence of depolarizing synaptic potentials with a crown of action potentials reminiscent of the paroxysmal depolarization shift during interictal spikes. The absence of cortical synaptic activity during EEG suppression has been attributed to extracellular calcium depletion from prior bursting activity. 12 The cycle repeats as calcium balance is restored by neuron pump activity. Earlier studies also showed $1-4 \mathrm{~Hz}$ rhythmic thalamic oscillations during cortical silence periods and a propensity for thalamocortical networks to produce burst activity even with subliminal stimuli. 13 The fact that ictal-like motor activity, such as myoclonus, may occur during EEG burst episodes lend support to the hyperexcitability theory. Cortical hyperex- citability has also been verified by intracranial recordings during anesthesia with BS-inducing barbiturate methohexital. ${ }^{14}$

Traditionally, BS has been viewed as a global state with widespread synchronous and homogenous cortical activation during the burst episodes and inactivation during the periods of suppression. ${ }^{15}$ This assumption is the basis for the clinical induction of $\mathrm{BS}$ to reduce global brain activity. In reality, the extent and spatial homogeneity of BS has not yet been fully explored because of the difficulty of recording multiple cortical sites simultaneously. Thus, the dynamics of large-scale cortical circuits during BS are not well understood. There is mounting evidence that BS is a local phenomenon. For example, intracranial EEG from patients under propofol anesthesia showed that BS can be asynchronous between cortical regions and can occur in limited cortical areas while other areas exhibit continuous activity. 16 This implies that local cortical dynamics are not homogeneous even during significant brain inactivation. It has been suggested that cortical and subcortical circuits have different sensitivities to anesthesia levels and that such a hierarchy governs how the brain enters BS during anesthesia. ${ }^{16}$

In both of our patients, unihemispheric BS was detected 30-45 minutes after clinical seizure termination with propofol and other anticonvulsants, persisted for 2-4 hours during propofol infusion at a rate of $2-3 \mathrm{mg} / \mathrm{kg} / \mathrm{hr}$, and disappeared when the rate was increased to 4$5 \mathrm{mg} / \mathrm{kg} / \mathrm{hr}$. It is conceivable that unihemispheric BS occurred because of pre-existing cortical hyperexcitability. Patient A had a metastatic tumor resected from the left temporoparietal region and Patient B was found to have a left parietal lobe lesion. It is also known that the anticonvulsant propofol can act as a proconvulsant depending on infusion rate and individual susceptibility. ${ }^{17-19}$ An infusion rate of $2-3 \mathrm{mg} / \mathrm{kg} / \mathrm{hr}$ may have facilitated, and a rate of $4-5 \mathrm{mg} / \mathrm{kg} / \mathrm{hr}$ may have suppressed, unihemispheric BS in both patients. The occurrence of unihemispheric $B S$ on the same side of a focal lesion after termination of a clinical seizure and its subsequent suppression with propofol alludes to cortical hyperexcitability as the primary mechanism underlying unihemispheric BS. It also supports the notion that BS is a product of abnormal local thalamocortical dynamics and that different networks have different thresholds for generating BS. It is provocative to think that unihemispheric BS shares some of the basic mechanisms of periodic lateralized epileptiform discharges and other periodic EEG discharges. ${ }^{20}$ It is not clear whether the above arguments about unihemispheric BS can be generalized to bihemispheric BS. Nevertheless, the most important question is not really whether cerebral hypometabolism or cortical hyperexcitability is the fundamental mechanism in BS. The two mechanisms are not mutually exclusive and there is some evidence that both are present in bihemispheric BS. It is also highly probable that both mechanisms are fundamentally essential to generate BS of any type. What is more important to know is whether BS-related thalamocortical overactivity constitutes an epileptic phenomenon and whether BS-related bursting activity is associated with restricted hypermetabolism exposing certain brain structures to the risk of additional brain injury. We hope that researchers will give us the answers to these questions in the near future. 


\section{Conclusions}

Burst suppression is typically bihemispheric and often bilaterally synchronous and symmetric. Unihemispheric $B S$ is rare but, as in the two cases presented, it can occur in association with seizures, propofol anesthesia, or both. It is not clear how unihemispheric BS is related to bihemispheric BS. The occurrence of unihemispheric BS with seizures and propofol anesthesia suggests that an epileptic mechanism is responsible for its generation. Whether an epileptic mechanism exposes certain brain structures to the risk of additional brain injury during unihemispheric BS, bihemispheric BS, or both is an important question that must be answered by future research.

\section{References}

1. Schaul N. The fundamental neural mechanisms of electroencephalography. Electroencephalogr Clin Neurophysiol 1998;106:101-7.

2. Niedermeyer E. The burst-suppression electroencephalogram. Am J Electroneurodiagnostic Technol 2009;49:333-41.

3. Ohtsuka Y, Ohno S, Oka E. Electroclinical characteristics of hemimegalencephaly. Pediatr Neurol 1999;20:390-3.

4. Lambrakis CC, Lancman ME, Romano C.
Asynchronous and asymmetric burst-suppression in a patient with a corpus callosum lesion. Clin Neurophysiol 1999;110:103-5.

5. Lazar LM, Milrod LM, Solomon GE, Labar DR. Asynchronous pentobarbital-induced burst suppression with corpus callosum hemorrhage. Clin Neurophysiol 1999;110:1036-40.

6. Ching S, Purdon PL, Vijayan S, et al. A neurophysiological-metabolic model for burst suppression. Proc Natl Acad Sci USA 2012;109:3095-100.

7. Edgren E, Enblad P, Grenvik A, et al. Cerebral blood flow and metabolism after cardiopulmonary resuscitation A pathophysiologic and prognostic positron emission tomography pilot study. Resuscitation 2003;57:161-70.

8. Levy WJ, Pantin E, Mehta S, McGarvey M. Hypothermia and the approximate entropy of the electroencephalogram. Anesthesiology 2003;98:53-7.

9. Hirsch N, Taylor C. Pharmacological and pathological modulation of cerebral physiology. Anaesth Intens Care Med 2010;11: 349-54.

10. Barash PG, ed. Clinical anesthesia. 6th ed. Philadelphia: Lippincott Williams \& Wilkins; 2009.

11. Steriade M, Amzica F, Contreras D. Cortical and thalamic cellular correlates of electroencephalographic burst-suppression. Electroencephalogr Clin Neurophysiol 1994;90:1-16.
12. Amzica F. Basic physiology of burst-suppression. Epilepsia 2009;50:38-9.

13. Kroeger D, Amzica F. Hypersensitivity of the anesthesia-induced comatose brain. $\mathrm{J}$ Neurosci 2007;27:10597-607.

14. Wennberg R, Quesney F, Olivier A, Dubeau F. Induction of burst-suppression and activation of epileptiform activity after methohexital and selective amygdalo-hippocampectomy. Electroencephalogr Clin Neurophysiol 1997;102:443-51.

15. Clark DL, Rosner BS. Neurophysiologic effects of general anesthetics. I. The electroencephalogram and sensory evoked responses in man. Anesthesiology 1973;38:564-82.

16. Lewis LD, Ching S, Weiner VS, et al. Local cortical dynamics of burst suppression in the anaesthetized brain. Brain 2013;136: 2727-37.

17. Walder B, Tramer MR, Seeck M. Seizure like phenomenon and propofol: a systematic review. Neurology 2002;58:1327-32.

18. San-juan D, Chiappa KH, Cole AJ. Propofol and the electroencephalogram. Clin Neurophysiol 2010;121:998-1006.

19. Cochran D, Price W, Gwinnutt CL. Unilateral convulsion after induction of anaesthesia with propofol. Br J Anaesth 1996;76:570-2

20. Kalamangalam GP, Diehl B, Burgess RC. Neuroimaging and neurophysiology of periodic lateralized epileptiform discharges: observations and hypotheses. Epilepsia 2007;48:1396-405. 